\title{
Ivan Boiko e a Bandura: o design e a construção de instrumentos
}

\section{musicais como símbolo cultural}

\section{Ivan Boiko and the Bandura: Musical instrument design and building as a cultural symbol \\ Juarez Bergmann Filho}

Doutor em Design pela Universidade Federal do Paraná (UFPR). Professor da Universidade Federal do Paraná (UFPR) juarezbergmann@gmail.com

\section{Resumo}

O presente artigo dialoga com múltiplas áreas do conhecimento em uma abordagem transdisciplinar, incluindo o Design, a Música, a Luteria e a Cultura Material. Esta pesquisa tem como objetivo documentar parte da história de vida de um artífice e alguns dos processos que levam à construção de instrumentos musicais, algumas significações e sentidos. O Método escolhido foi o da revisão bibliográfica e da História Oral, por meio de entrevistas semi estruturadas. Como exemplo, apresenta-se o caso do artífice Ivan Boiko, que influenciado por elementos tanto de sua cultura natal ucraniana, como da brasileira, passou a construir banduras utilizando materiais e ferramentas locais, desenvolvendo assim projetos e conceitos próprios, incorporados ao longo de muita experimentação. Como resultado o artigo aponta para uma busca das trajetórias dos artefatos, como uma ferramenta de análise e observação, que deve passar também pela trajetória (de vida e laborais) de seus artífices construtores. Observar a trajetória de Ivan Boiko e da Bandura pode servir como contextualização de elementos culturais que influenciam a criação, produção e significação da cultura material. Espera-se assim, compreender melhor a complexidade de elementos que podem influenciar direta ou indiretamente a construção de um artefato.

Palavras-chave: Instrumentos musicais. Cultura material. Luteria.

\begin{abstract}
The present paper dialogues with multiple areas of knowledge in a transdisciplinary approach. It includes the disciplinary areas of the Design, the Music, the Lutherie, and the Material Culture. This research aims to understand some of the processes that lead to the construction of musical instruments and how these artifacts incorporate and emanate meaning. The method chosen was that of bibliographic review and oral history, through semi-structured interviews. As an example, the case study of the craftsman Ivan Boiko was selected. His work was influenced by elements of both his native Ukrainian culture and Brazilian culture, where he started building the musical instrument called Bandura using local materials and tools, thus developing his own projects and concepts, incorporated through experimentation over a long period of time. As a result, the article points to the artifact's trajectories, as a tool for the analysis and observation, which must also go through the trajectory (of life and work) of its builders. Observing the trajectory of Ivan Boiko and the Bandura, may serve as contextualization of the cultural processes and elements that influence the creation, production and significance of Material Culture. It is hoped, therefore, to better understand the complexity of elements that can directly or indirectly influence the construction of an artifact.
\end{abstract}

Keywords: Musical instruments. Material Culture. Lutherie.

Recebido em: 02/04/2018

Aceito em: 18/07/2018 


\section{INTRODUÇÃO}

Quando grandes massas populacionais são forçadas ao deslocamento, passam por um forte processo de troca e re-significação cultural ao longo de sua jornada. Conceitos sobre a pátria mãe são reconstruídos e práticas antes comuns ao dia-a-dia passam a ser entendidas em uma nova esfera de importância. Artefatos designam novos valores e são criados a partir de novos conceitos, refletindo a luta de um grupo de pessoas para manter e recriar suas tradições e costumes. No estado do Paraná, grupos de ucranianos ${ }^{1}$ exilados de guerra, estabeleceram-se em diversos locais a partir do final década de 1940. Em sua trajetória até o Brasil, testemunharam o totalitarismo soviético, a partir do qual Ihes foram retirados praticamente todos os bens, passaram por campos de concentração nazistas no qual testemunharam o horror causado pela intolerância e foram forçados ao trabalho escravo e finalmente, por meio da propaganda de um governo nacionalista acabaram aportando ao Novo Mundo.

Por meio de narrativas individuais, é possível compreender um pouco melhor este processo, aqui detalhado na trajetória do senhor Ivan Boiko e a construção da Bandura². Entender tais relatos pode contextualizar melhor as diversas circunstâncias que levam a criação de um artefato, pois tais heranças culturais são (re)transmitidas, (re)lidas e (re)significadas, pelas gerações seguintes, em um estado caracterizado pela pluralidade cultural de seu povo, fortemente influenciado por imigrantes de várias nacionalidades.

Os dados aqui levantados são fruto de uma revisão bibliográfica sobre a cultura material, em especial aquela que trata do estudo de instrumentos musicais. Acrescido a isso, duas sessões de entrevistas semi estruturadas foram realizadas na residência do senhor Ivan Boiko (figura 1), no bairro do Bigorrilho em Curitiba- PR. Este artigo fala de trajetórias, narrativas, significados e simbolismos culturais. O texto está inserido no tema da Cultura Material, e através de narrativas

\footnotetext{
1 Sobre a trajetória da imigração ucraniana no Paraná, assim como detalhes da cultura, religião e outros costumes ver GUÉRIOS (2012).

${ }^{2}$ A Bandura é um instrumento ucraniano que remonta ao século VII. Ele foi originalmente utilizado para acompanhar baladas e danças folclóricas e tornou-se popular entre os séculos XV e XVIII, com os músicos viajantes chamados Kobzars, que cantavam sobre as façanhas dos cossacos. A Bandura é na verdade um tipo de cítara constituída de 21 até 55 cordas metálicas, dedilhadas como uma harpa e tocadas na posição vertical. Pode ser caracterizada como um cruzamento entre um grande alaúde e harpa celta. Seu som se assemelha ao de um cravo. A música mais tradicional ucraniana inclui a Bandura, porém durante a ocupação soviética da Ucrânia caiu em desuso, já que atuava como o símbolo da cultura nacional ucraniana e assim foi raramente foi tocada em público durante o período de ocupação (NEDEL, 2004).
} 
sobre trajetórias laborais, procura compreender melhor os contextos de criação, apropriação e significação de artefatos, aqui exemplificados por instrumentos musicais e por fragmentos do relato e da história pessoal do Senhor Ivan Boiko.

Figura 1 - Ivan Boiko.

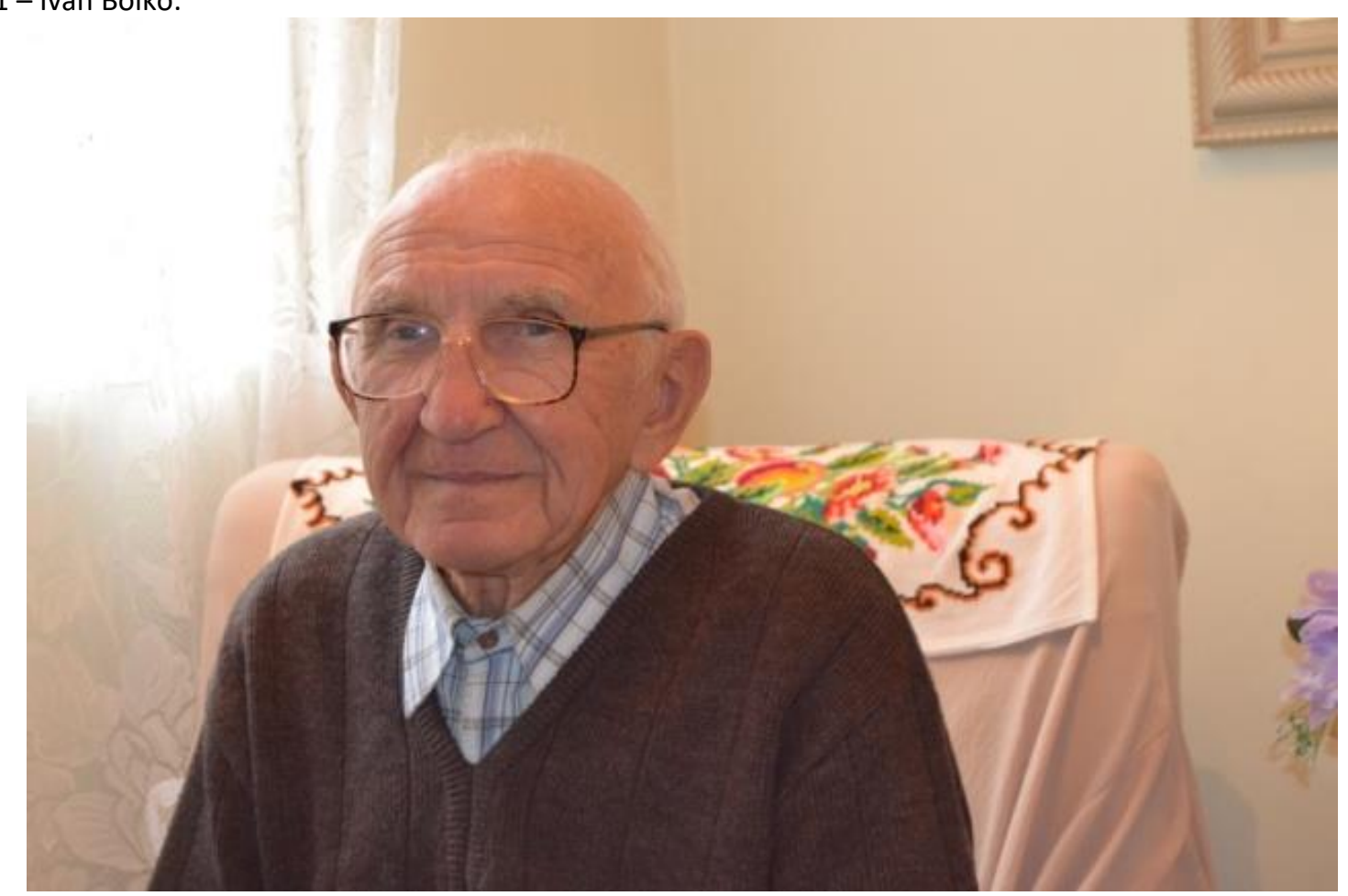

Foto: autor.

\section{PROCEDIMENTOS METODOLÓGICOS}

O método aplicado na coleta de dados foi o da história oral, a partir de entrevista realizada com o senhor Ivan Boiko. Ao todo foram feitas três visitas à residência do entrevistado, na primeira delas, intermediada pelo diretor e documentarista Guto Pasko, uma conversa informal pôde ser registrada tanto na sala da residência quanto na oficina do entrevistado, totalizando sessenta minutos de gravações fragmentadas. Posteriormente, na segunda visita, aconteceu uma entrevista de caráter semi-dirigido em que grandes temas relacionados à trajetória do entrevistado, observados e anotados na primeira visita, puderam ser abordados de forma mais direta. 0 encontro foi registrado em mídias digitais de áudio e vídeo, com duração total de 40 minutos. A última visita ocorreu para melhor esclarecer alguns detalhamentos e mostrar ao interlocutor alguns trechos de áudio transcritos e resultados preliminares dos encontros anteriores. 
Uma folha de temas e perguntas foi preparada para a melhor condução da entrevista, mas não chegou a ser usada, já que o relato do senhor Boiko naturalmente abordou as questões propostas. Na sessão de entrevistas o interlocutor se mostrou bastante à vontade em seu relato, e com seus 93 anos de idade também mostrou muita energia e disposição, deixando pouco espaço para perguntas, já que logo que o entrevistador fazia uma interseção era prontamente interrompido pelo entrevistado que prosseguia com seu relato.

Os temas evidenciados no discurso de Ivan Boiko circundam uma grande área da Cultura Material, e abrangem tópicos tão variados quanto o da biografia laboral e da biografia de artefatos, da construção de instrumentos musicais e, sobretudo, da relação entre o homem e o trabalho. Este artigo aborda apenas parte dos temas evidenciados nestes encontros.

\section{A CONSTRUÇÃO, POR IMPULSO?}

Com frequência encontramos relatos de pessoas, que começam a se dedicar a uma atividade especializada, como que por acaso em um impulso aparentemente espontâneo. Muitas vezes, sem ter em suas trajetórias anteriores qualquer ligação direta com a área aventurada. Refirome neste caso específico ao trabalho manual da construção de instrumentos musicais, mas outros exemplos, não somente regionais, mas nacionais e internacionais também podem ser lembrados. Cito aqui alguns os exemplos de tais processos de criação: Em uma reserva indígena da Costa Rica, o construtor Memerto Ortiz relata que, ao se deparar com uma imagem de um violino em um jornal local, sentiu o ímpeto de construir tal instrumento (ACEVEDO, 1986), como resultado, Ortiz fabricou a sua leitura e versão daquele instrumento europeu. Neustadt (2007), analisando tal fenômeno, argumenta que o construtor Ortiz, faz uma imagem de uma cópia de um instrumento europeu, e assim cria seu próprio "original" a partir de soluções e materiais consequentes a tal processo construtivo.

No Brasil, tal artifício pode ser exemplificado pelo caso das violas e rabecas brasileiras, que em suas trajetórias híbridas influenciadas por elementos europeus e mais especificamente portugueses, foram relidos e recriados em nosso país (TRAVESSOS, 2006). O construtor de rabecas, Nelson "da rabeca" dos Santos, natural do estado do Alagoas, hoje um reconhecido mestre artesão do instrumento relata que após trabalhar por mais de cinquenta anos como cortador de cana em uma lavoura, sentiu a vontade de construir rabecas, desenvolvendo por meio de experimentação 


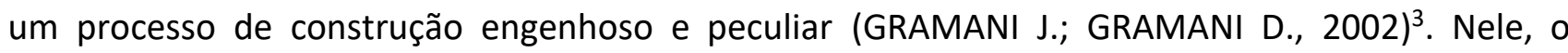
artífice utiliza madeiras nativas da região, principalmente aquela proveniente da raiz da jaqueira, entalhada predominantemente com um facão habilmente manuseado por Nelson, fruto de décadas de uso da ferramenta no ofício agrícola nas colheitas da cana-de-açúcar.

Para Neustadt (2007), neste processo de criação não existem resoluções ou fórmulas prontas, pois as diferentes negociações são inerentes a todas as formações de identidades e especialmente visíveis nas culturas latino-americanas, devido à sua característica de mestiçagem (hibridismo) cultural. O autor parte da visão dos estudos culturais, e a perspectiva de análises de usos específicos de artefatos, neste caso instrumentos musicais, com o intuito de traçar uma linha de construção de identidades - nacionais, regionais e locais. Dentro desta perspectiva, o processo de negociação transcultural é particularmente evidente em diversas práticas que tem adaptado instrumentos musicais europeus, construindo seus próprios originais com os quais se expressam. Assim sendo, carregam em si referenciais diferentes daqueles tradicionalmente europeus, sejam em técnicas de construção, materiais utilizados, processos de produção e significados.

De fato, alguns instrumentos construídos em nosso país se assemelham, por vezes superficialmente, aos seus protótipos europeus. Cito o caso das rabecas e violas brasileiras, que apesar de serem construídas com a intencionalidade, referências plásticas e algumas vezes estruturais de instrumentos europeus, são concebidas de forma a produzirem sons totalmente distintos, adaptados às suas realidades musicais e culturais específicas. Portanto, estas observações também são válidas às Banduras construídas pelo senhor Boiko, já que seus instrumentos apresentam igualmente semelhanças e diferenças entre as banduras construídas na Ucrânia ${ }^{4}$.

Para Neustadt (2007), tais modificações em artefatos musicais provavelmente ocorrem de forma inconsciente, sendo transformados e consolidados através de anos de experimentalismos marcados pelas misturas culturais e musicais. Com o construtor Ivan Boiko, natural da Ucrânia e radicado em Curitiba, algo similar aconteceu. Apesar do construtor não ser de origem nativa brasileira, e sim europeia, toda a sua experiência como construtor se deu no Brasil. De certa forma, teve que lidar com as mesmas dificuldades que outros artífices de nosso país, como a adaptação de

\footnotetext{
${ }^{3}$ Este livro é fruto das pesquisas de José Eduardo Gramani e foi organizada por sua filha Daniella e postumamente publicada no ano de 2002.

${ }^{4}$ Sobre a complexa cultura musical da bandura ucraniana, recomenda-se a leitura de Kononenko (1998).
} 
técnicas e materiais aqui disponíveis, incorporando um repertório técnico a partir de referenciais próprios de sua trajetória.

Após sair de sua terra natal, por interferência soviética e passar por uma trajetória longa e conturbada, acabou migrando para o Brasil, juntamente com sua esposa Anna que conheceu em plena Alemanha nazista.

\begin{abstract}
- Nasci na terra ucraniana, vivi lá na terra ucraniana por 22 anos. Depois de 22 anos... em 1942, fui transportado para Alemanha nos serviços forçados. Eu fiquei lá até terminar a guerra. Depois, quando a guerra terminou, algumas pessoas, que foram para os serviços forçados, começaram a voltar para a pátria deles... Esse assunto não é só meu, foram centenas e centenas de pessoas, não é? 0 que eles não aceitaram e eu também não, era o regime soviético. Como a Ucrânia foi ocupada pela União Soviética, eu vi aquele regime, e não gostei. $\mathrm{E}$ eu, assim como outros daquele grupo, como se chama...fugitivo? - refugiados - $O$ grupo não aceitou voltar.

Então depois, os americanos fizeram uma sociedade, como se chama? Cruz Vermelha! o Brasil também estava incluído naquela Cruz Vermelha, para proteger aquele fugitivo (refugiado). Porque eles não queriam voltar forçados para o lar deles ${ }^{5}$. Eu entrei também na Cruz Vermelha, esperei até... minha vez, como todo mundo esperou, não é? Receber um lugar para imigrar. Esperei de (19)45 até (19)48. Veio um pessoal representante do Brasil e outro de idioma francês, ele escreveu gente que havia, já para ir ao Brasil. Eu me alistei também. Ele perguntou sobre minha família... eu e três pessoas. E em 1948 eu recebi a ordem. Posso viajar para o Brasil!" (BOIKO, ENTREVISTA 02, 2013).
\end{abstract}

Os portos de entrada para estrangeiros no Brasil eram os de Salvador, de Santos e do Rio de Janeiro. Os imigrantes que chegavam pelo porto do Rio de Janeiro, passavam primeiro pela triagem da Agência Central de Imigração, e então eram encaminhados para a Hospedaria da Ilha das Flores, onde recebiam tratamento médico, comida e direcionamento para outra cidade ou fazenda para trabalharem.

\footnotetext{
“-Em 1948, no mês de abril eu cheguei ao Brasil, na região do Rio de Janeiro, na llha das Flores. Eu queria ficar no Rio, gostei do Rio! Como eles nos levaram para conhecer o Rio de Janeiro. Tinha um cidadão.... um cozinheiro, ele falava um pouquinho, mais ou menos o idioma italiano, como idioma italiano inclui um pouquinho de português, o tradutor disse pra mim: "Olha, é melhor você ir para o Paraná. (O) Lugar melhor (para você) é o Paraná e Curitiba, porque lá naquele lugar é um clima bom pra vocês, gente da Europa. Lá tem gente de todas as nacionalidades. Como você veio agora, e domina dois ou três idiomas, você pode se comunicar, eu te aconselho, vai para o Paraná!". E eu vim para o Paraná. E procurei serviço... (BOIKO, ENTREVISTA 02, 2013)
}

\footnotetext{
${ }^{5}$ Após a guerra, e ainda ocupados pelo regime Soviético, muitos Ucranianos que estiveram nos campos nazistas foram acusando de inimigos do povo e traidores. O senhor Ivan Boiko corria o risco de ser executado quando voltasse para sua terra natal ou enviado para os campos de trabalhos forçados soviéticos.
} 
Chegando em Curitiba, buscando formas de se adaptar à nova vida encontrou refúgio no trabalho e na igreja, procurando relacionar-se primeiramente com as pessoas filiadas às Sociedades Ucranianas formadas na capital paranaense.

- (Entrevistador) E o senhor veio pra Curitiba mesmo?

- Curitiba direto. Quando eu cheguei em Curitiba, no primeiro dia eu perguntei: tem Igreja ucraniana aqui por perto? Tem! Tem Sociedade (ucraniana) também? Tem. É Longe? Não, aqui a três quadras! Então tinha a Sociedade Ucraniana e eles nos acolheram, não é? Aquele grupo que veio junto comigo, nem me lembro de quantas pessoas éramos... Um grupo! E já no primeiro domingo quando eu cheguei na Igreja, sem dominar o idioma, todo mundo na rua (disse)... "entra na igreja, eles são conhecidos e tal" e eles falavam idioma em português, não é?

- (Entrevistador) Sim...

-Aí uma senhora... já falecida, disse: "Vocês podem me dizer, vocês vieram da Europa?" Vim sim senhora. - "Então vem no Coral cantar junto com a gente". Foi daquele dia que comecei a entrar, assim, como participante da comunidade. Já entrei na Sociedade. Um grande Coral, as músicas, e assim na participação no folclore. Sempre! Todos os anos... sempre participei... E assim foi indo minha vida, até 1960... (BOIKO, ENTREVISTA 01, 2013)

Sua participação no Coral da Igreja Ucraniana proporcionou um caminho de entrada e aceitação em um circuito social. A partir deste momento, sua relação com as pessoas deste circuito se consolidou, sua rede de contatos se ampliou e ele começou a trabalhar. Aqui na capital paranaense, Ivan Boiko buscou várias linhas de trabalho, aproveitando as oportunidades que apareciam.

- (Entrevistador) E o senhor trabalhava aqui, com o que seu Ivan? Aqui em Curitiba.

- Minha profissão era tudo. Tudo o que eu podia pegar eu fazia, para sobreviver. Ajudava também. Alguém assim que fazia alguma coisa, eu ajudava para aprender. Eu trabalhei em sapataria, trabalhei como marceneiro, mas marceneiro só seis meses, trabalhei, assim, do lado de alfaiate, ajudante de pedreiro. Tudo o que podia para sobreviver!" (BOIKO, ENTREVISTA 02, 2013).

O fragmento acima evidencia a disponibilidade de trabalhar do senhor Ivan, aproveitando estes momentos para constituir seu lugar na sociedade, já que o trabalho lhe proporcionava uma oportunidade de se relacionar com pessoas diferentes. Estes trabalhos variados também proporcionaram ao senhor Boiko uma gama de repertório laboral, principalmente em atividades que exigiam habilidades manuais. Este conhecimento mostrou-se futuramente útil na construção dos instrumentos musicais. Atividade que viria a seguir. 


\title{
3.1 FINALMENTE, A BANDURA! E COMO FAZER?
}

Após mais de uma década no Brasil, trabalhando informalmente em diversos ofícios que apareciam, finalmente Ivan Boiko começa seu projeto de construção da bandura. Esta atividade vai definir o lugar do artífice nos meios sociais que ele vivia.

\footnotetext{
- E assim foi indo minha vida, até $1960 \ldots$ sempre aquele maestro do Coral se queixava, ele disse: Como veio a imigração, a primeira, a segunda e veio a terceira (geração de imigrantes), como chama-se? Imigrantes políticos! E ninguém trouxe o instrumento bandura?

- (Entrevistador) Ah, esse maestro que falou (da bandura)...

- Sim... É porque lá na nossa canção, tem uma canção que eu sempre cantava, uma famosa canção, que fala de banduras, ...então eu recebi um jornal. Aquele jornal veio da Ucrânia! E lá nas homenagens tinha uma foto (de um coral)... Tinha umas, mais ou menos, eu acho que umas 50 ou mais pessoas, e tinha na frente do coral as banduras e banduristas, e eu olhei; O que é isso?! Eu escutei as histórias de banduristas ucranianos, só não tinha visto um na minha vida.

- (Entrevistador) Sei...

- Como o instrumento é feito? Nunca tinha visto nem um retrato nem nada.

- (Entrevistador) O senhor conhecia o nome do instrumento, mas nunca tinha visto...

- Sim. E ainda mais com aquele jornal, apagado, escuro... e isso me bateu, bom... a vontade de fazer. E como é fazer? Sempre olhava aquele jornal... e então eu fiz. Não sou marceneiro e não sou maestro da música, só participante do coral, não é? Mas com meu jeitinho comecei a fazer (BOIKO, ENTREVISTA 02, 2013).
}

Ivan relata que nunca havia sequer visto o instrumento chamado de Bandura, porém sentiu a necessidade de construir tal artefato, que simbolizava a cultura de seu povo:

\begin{abstract}
“- A minha iniciação como artesão de bandura aconteceu há muito tempo, aconteceu espontaneamente, surgindo de uma ideia simples... mas não foi nada simples e fácil. $\mathrm{Na}$ minha vida, até então, eu nunca tinha visto e segurado nas mãos o instrumento, nunca fui músico e também nunca fui um marceneiro ou praticado alguma atividade relacionada com o artesanato de madeira" (BOIKO, 1984).
\end{abstract}

Porém Boiko relata que, apesar das dificuldades encontradas a vontade e talvez a necessidade de construir algo, tão representativo para ele e seu passado, o levou a buscar maneiras de concretizar o instrumento, como mostra o relato publicado em um jornal da década de 1980:

\footnotetext{
“- Mas mesmo assim eu resolvi fabricar banduras e pus as mãos à obra. O começo foi bastante difícil. Antes de mais nada comecei a conversar com pessoas, procurar nas bibliotecas a literatura e informações. Não foi muito, e também não havia ninguém capaz ou disposto a ajudar. Mas o tempo foi passando e minha bandura começou a tomar corpo, acabando de nascer. A seguir, apareceu a segunda, depois a terceira e assim fui
} 
aprendendo e aperfeiçoando o instrumento cada vez mais. Enquanto isso, não parei de procurar fontes e notícias sobre os instrumentos populares ucranianos, sobre músicas e antigas canções..." (Boiko 1984).

Figura 2 - Ivan Boiko em seu local de trabalho.

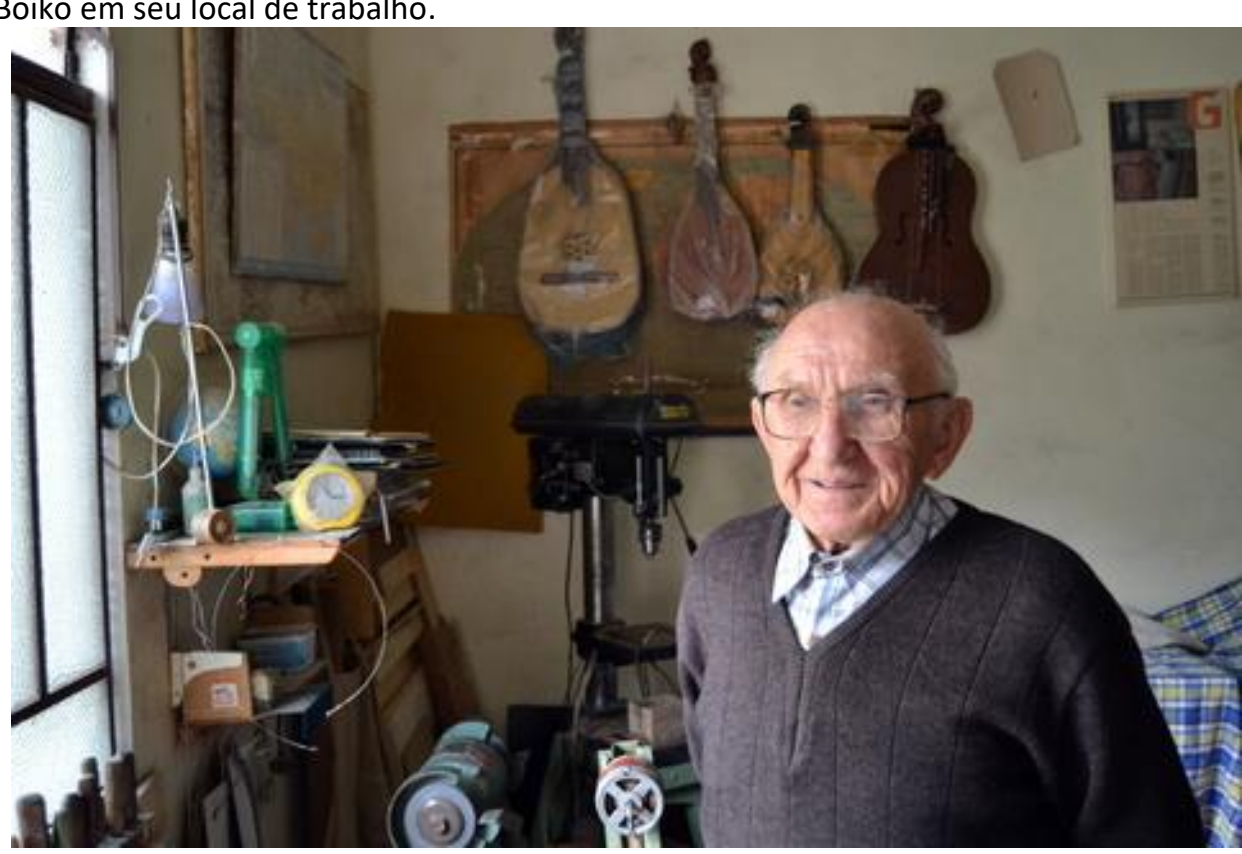

Foto: autor.

A abordagem de Boiko ao projeto mostra traços de similaridades com os outros casos apresentados anteriormente. A própria ausência da técnica tradicional de construção destes artefatos, além de materiais e ferramentas apropriadas, exigiu destes construtores uma série de soluções engenhosas, para que vencessem várias barreiras no processo de construção.

- Em 61 eu trabalhei já naquela bandura. Em 62 já mostrei a bandura na homenagem a Taras Schevchenko, na sociedade ucraniana, não é? E já; aquele povo aplaudiu, já viu que era uma coisa que valia, e como todo mundo também nunca viu, ninguém nunca viu a bandura, não é? Já começaram a vir pedir para mostrar como é a bandura... (BOIKO, ENTREVISTA 02, 2013).

Em seu discurso, Boiko evidencia as dificuldades que enfrentou no processo de construção e na aquisição de ferramentas, e como desenvolveu praticamente sozinho a atividade.

- (Entrevistador) Então voltando, seu Ivan, para a parte da construção, o senhor comentou que viu de um jornal e a partir daí o senhor começou (a construir), o projeto todo é seu? - É totalmente meu, ninguém ajudou em nada. NADA. E eu não tinha ferramenta, não tinha, depois montei uma lixadeira... serrote manual e foi. 
- (Entrevistador) O senhor não tinha as medidas, nada?

- Nada, nada, nada. Domingo de noite, ou quando eu podia no meio de um serviço eu tinha aquele cantinho bem pequeninho... e naquele cantinho eu ia e vai, vai... (faz um gestual de como se estivesse serrando uma madeira). No domingo todo mundo ia para missa e o Ivan sempre construindo e batendo... o Ivan não deu sossego para o vizinho.

- (Entrevistador) Sempre fazendo barulho...

- E depois devagar tive a consciência que tinha que comprar mais ferramentas, pois sempre falta... e falta até hoje. Falta... para fazer uma coisa falta muito... aqui assim só no "machado"... depois eu tinha um filme de como se faz bandura. E aquela serra fita que tenho, foi quando trabalhei na firma da polícia militar, lá tinha uma cooperativa, e tinha duas serras fita. Tinha um açougue que fornecia para a sociedade deles. E quando fecharam eu cheguei para o coronel e pedi se era possível eles venderem para mim aquela serra fita... Depois do almoço ele disse olha Ivan, pega a Kombi, duas ou três pessoas e pode pegar a serra fita. Eu peguei esta serra fita e trouxe para casa, depois precisava de furadeira... furadeira eu tinha a manual, depois o Nilton (genro) comprou para mim a furadeira eletrônica (elétrica)... depois ele trouxe uma estante (bancada) para por aquela furadeira eletrônica. Depois ele comprou o compressor novo... eu tinha um pequeno assim... (BOIKO, ENTREVISTA 02, 2013).

\title{
O experimentalismo encarnado nas tentativas e erros desta trajetória, levam os
} construtores a desenvolver estilos particulares. Ivan Boiko mostra em seu relato, uma grande disposição em construir o artefato, em pesquisar e aprimorar. Porém, também demonstra uma preocupação muito grande com a continuidade de seu trabalho, e o risco da atividade se perder no futuro.

\begin{abstract}
- Então para fazer bandura tem que ter ferramenta. O tamborzinho, não é, porque uma porção não existe mais, que é cavocar, eu vi como é , como foi feito... é fácil, só precisa de dinheiro para fazer... todo este eletrônico que ele precisava pôr, para cozinhar aquela pranchina... depois aquele também.... aquele tamborzinho tipo melancia, né, que eles colam assim... isso! Tenho na memória tudo, é só fazer!. Eu sou muito curioso. Só que aqui precisa vender a casa para montar... (uma oficina equipada). E estou vendo agora, você está vendo como eu faço, meu esforço assim como posso, falta muita coisa para caprichar, só precisa de muito experimento. Só que ninguém faz melhor, porque ninguém se interessou até agora... e quantos meses....eu falei quantas vezes e sempre falo. Falei e falo: E quando o velho Boiko morrer? Quem vai fazer? Olha trouxeram para mim montes de arames para eu fazer cordas para eles, pra Sociedade (Ucraniana) e para as banduras, porque arrebentam... eu disse: olha, hoje eu posso fazer e amanhã? E depois de amanhã quando minha idade vem.... 95 anos? Essa energia está acabando (BOIKO, ENTREVISTA 02, 2013).
\end{abstract}

Analisando diversos contextos da cultura material brasileira, Magalhães (1997) observa algumas características e similaridades, aqui neste artigo exemplificadas mais claramente no caso da construção da Bandura pelo artífice Ivan. Magalhães (1997 ,p. 180) argumenta: 
O que parece existir é uma disponibilidade imensa para o fazer, para criação dos objetos. Parece-me que no caso brasileiro nós poderíamos dizer que toda a atividade com características de artesanato, ou seja, relação muito direta entre idéia e concretização, pequena intermediação entre a ideia e o objeto final, são formas iniciais de uma atividade que quer entrar na trajetória do tempo. Quer evoluir na direção de maior complexidade e de resultados mais efetivos. ... e na observação desses valores, desses indicadores, tentar acompanhar a evolução desse processo. E introduzir nesse processo condições para que ele se desenvolva com harmonia.

Magalhães aponta para a vontade de construir e salienta as trajetórias deste processo como importantes. Entendo por trajetórias, tanto aquelas biográficas dos construtores, neste artigo mais especificamente as laborais, como também as trajetórias do processo de construção e consequentemente do artefato. Magalhães (1997, p. 181) continua:

É possível até ir-se mais adiante e dizer que esta evolução na direção de uma maior complexidade, de uma maior elaboração, caracterizada por um índice de invenção, como sendo uma atitude de pré-design. Em outras palavras, o artesão brasileiro é basicamente um designer em potencial, muito mais do que propriamente um artesão no sentido clássico. Isto pode criar conflitos na medida em que se sentindo muitas vezes basicamente um homem do século XIII, ele tem que conviver com informações, com elementos cotidianos, e com técnicas que são de outro espaço e tempo, ou seja, já do século XX. Daí o conflito, a dificuldade para se entender, se situar. E ele sobrevive graças a grande disponibilidade, a que me referi antes: isenção e invenção.

Esse processo fica evidente nas narrativas de Ivan Boiko. Quando o construtor relata as dificuldades de construir, os problemas de acesso a informação específica de construção, a falta de referenciais, ou seja, a "isenção" deste conhecimento. Acaba-se necessário o uso da intuição e consequentemente a transposição de tais limitações com o uso de uma séria de artifícios, caracterizados por invenções e inovações.

\section{CONSIDERAÇÕES FINAIS}

Por meio da história oral, e das narrativas pessoais, é possível compreender um pouco melhor os contextos que levaram a formação de um fenômeno, aqui incorporado pelo caso do surgimento da Bandura de Ivan Boiko. Este artigo apresentou tão somente fragmentos da trajetória de Ivan. Não foi possível dar conta de uma série de temas que apareceram em suas narrativas. Aspectos específicos da construção das banduras, escolha de materiais, ferramentas utilizadas, performance musical, entre outros, tiveram que ser deixados de lado devido ao recorte proposto para este artigo. Por outro lado, entender trajetórias específicas no processo de elaboração de 
instrumentos musicais, nos faz compreender que para conhecermos os artefatos e seus significados, devemos buscar entender também quem os construiu, como o fez, por que e para que (ou para quem) construiu. A busca pelas trajetórias dos artefatos deve passar também pela trajetória de seus artífices, e vice e versa. Esta procura é ao mesmo tempo dinâmica e transcultural, exigindo a observação a partir de pontos de vista distintos. É impossível apontar com precisão quais pessoas o trabalho de seu Ivan alcançou, e quantas influenciou. Porém pode-se constatar que sua atitude perante o projeto, a busca por aperfeiçoamento constante, o comprometimento com o artefato e seu significado o caracterizam como um pioneiro da luteria paranaense e consequentemente uma atitude pioneira para a área do design. Entrevistar o senhor Ivan Boiko foi uma experiência única, sua dedicação ao ofício e a busca pessoal por aprimoramento constante ao seu projeto, mesmo aos 93 anos, são inspiradores.

O artífice Ivan Boiko faleceu na noite de Natal do ano de 2016. Este artigo é em sua homenagem.

\section{REFERÊNCIAS}

ACEVEDO, Jorge Luis. La musica en las reservas indigenas de Costa Rica. San Jose: Editorial de la Universidad de Costa Rica, 1986.

BOIKO, Ivan. Entrevista feita por Juarez Bergmann Filho. Entrevista 01. Curitiba, 22 de abril de 2013.

2013.

. Entrevista feita por Juarez Bergmann Filho. Entrevista 02. Curitiba, 06 de Setembro de

. Sobre Kobza, Bandura e Lira. Documento pessoal do autor. Curitiba, 15 de Junho de 1984.

DAWE, Kevin. The cultural study of musical instruments. In: CLAYTON, Matin; HERBERT, Trevor; MIDDLETO, Richard (Ed). The cultural study of music: a critical introduction. New York; London: Routledge, 2011. Cap. 23.

GRAMANI, José Eduardo; GRAMANI, Daniella. Rabeca, o som inesperado. Curitiba: Fundação Cultural de Curitiba, 2002.

GUÉRIOS, Paulo Renato. A imigração ucraniana ao Paraná: memória, identidade e religião. Curitiba: UFPR, 2012. 
KONONENKO, Natalie O. Ukrainian minstrels: and the blind shall sing. New York: M.E. Sharpe, 1998.

MAGALHÃES, Aloísio. E Triunfo?: A questão dos bens culturais no Brasil. Rio de Janeiro: Nova Fronteira, 1997.

NEUSTADT, Robert. Reading indigenous and mestizo musical instruments: the negotiation of political and cultural identities in latin america. Music \& Politics, v. 1, n. 2, 2007. ISSN 1938-7687.

NIDEL, Richard. World music: the basics. New York: Routlege, 2004.

TRAVASSOS, Elizabeth. $O$ destino de artefatos musicais de origem ibérica e a modernização no Rio de Janeiro (ou como a viola se tornou caipira). In: SANTOS, Gilda; VELHO, Gilberto (Org.). Artifícios \& artefactos: entre o literário e o antropológico. Rio de janeiro: 7 letras, 2006. p. 115-134.

\section{ANEXOS}

Figura 3 - Ivan Boiko em seu atelier.

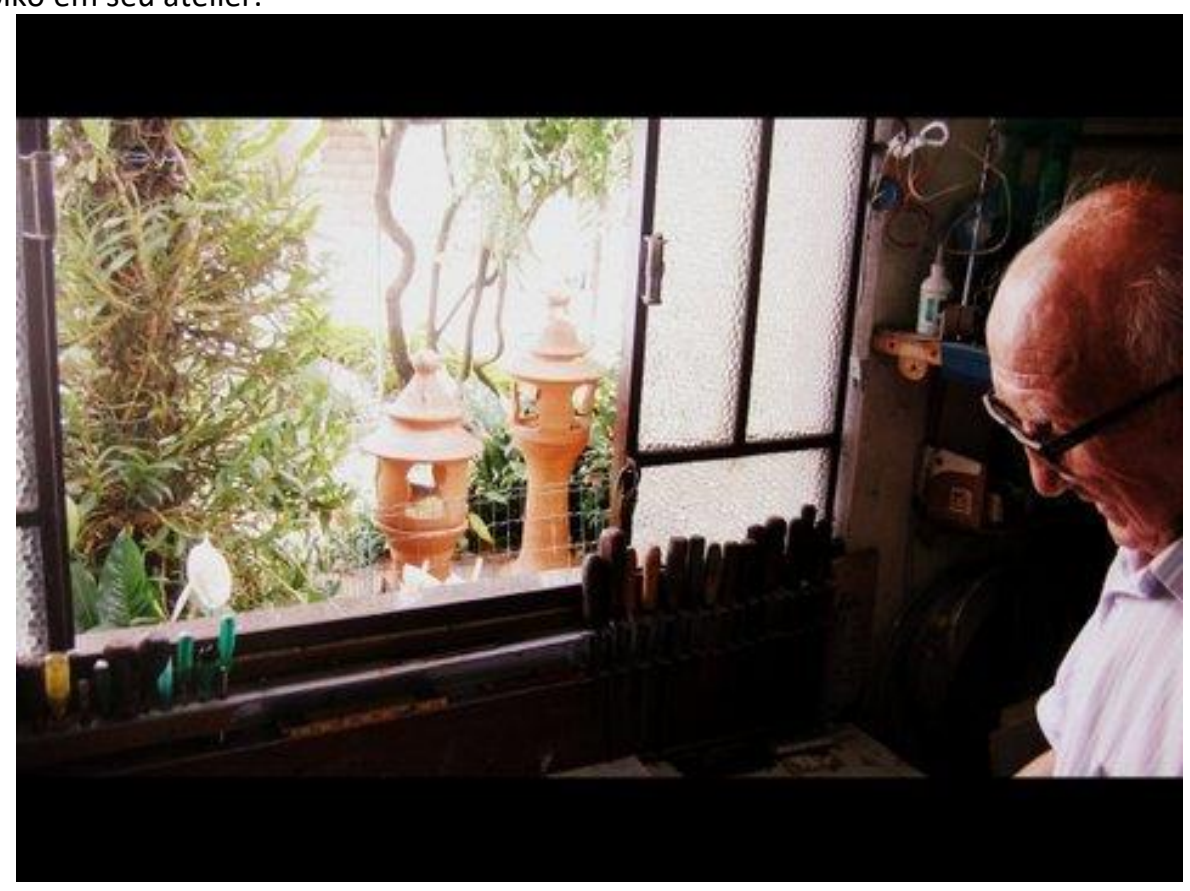

Foto: autor. 
Figura 4 - Bandura.

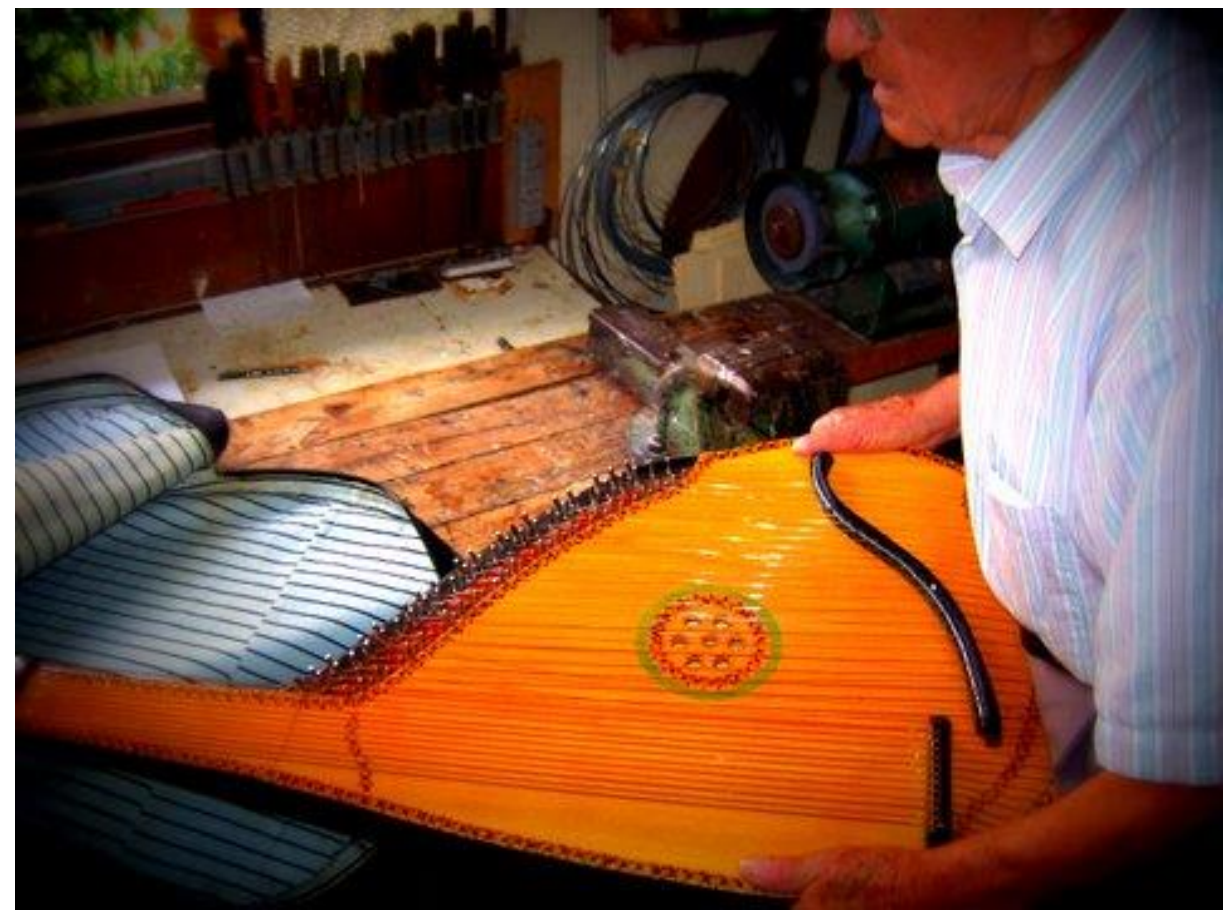

Foto: autor.

Figura 5 - Detalhe da bandura.

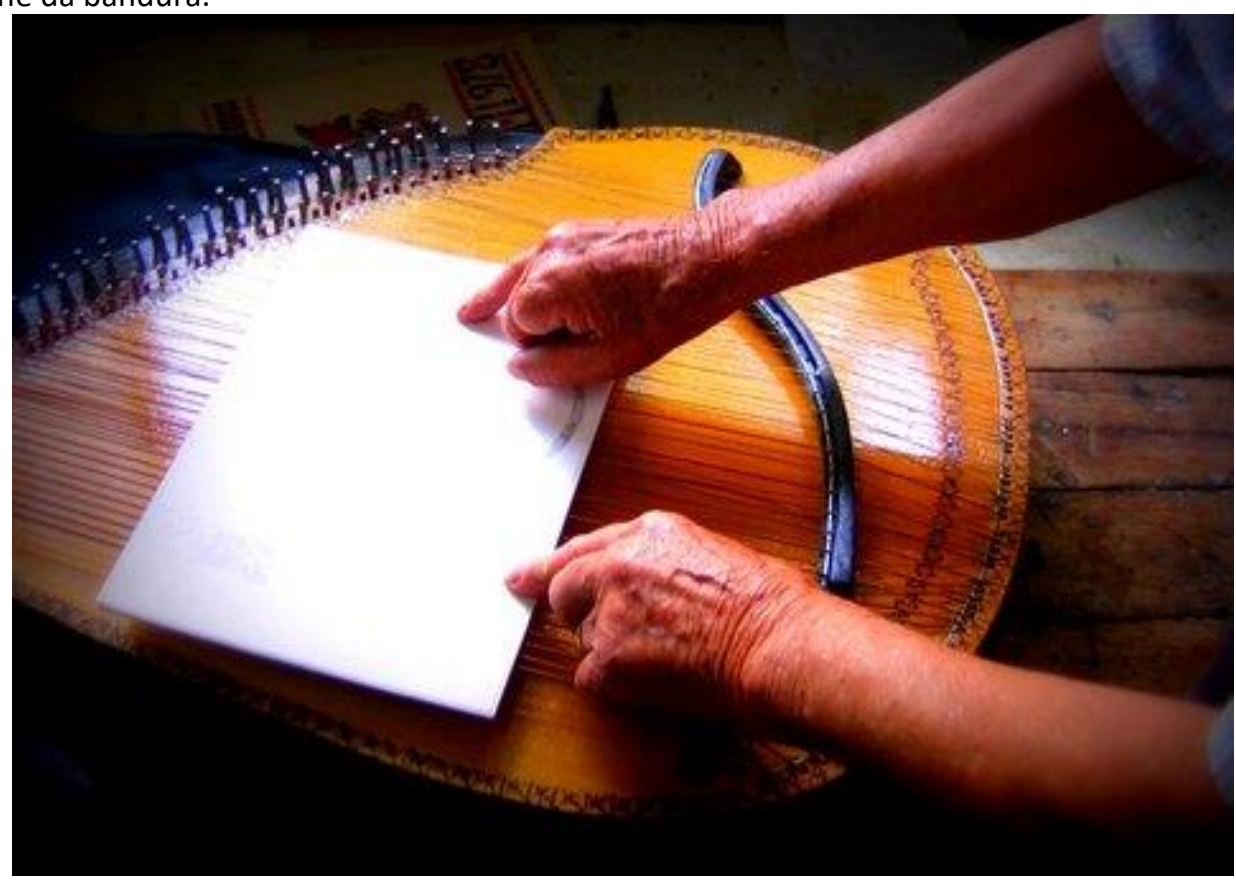

Foto: autor. 
Ivan Boiko e a Bandura: o design e a construção de instrumentos musicais como símbolo cultural Juarez Bergmann Filho

Figura 6 - Adornos marcados com pirógrafo.

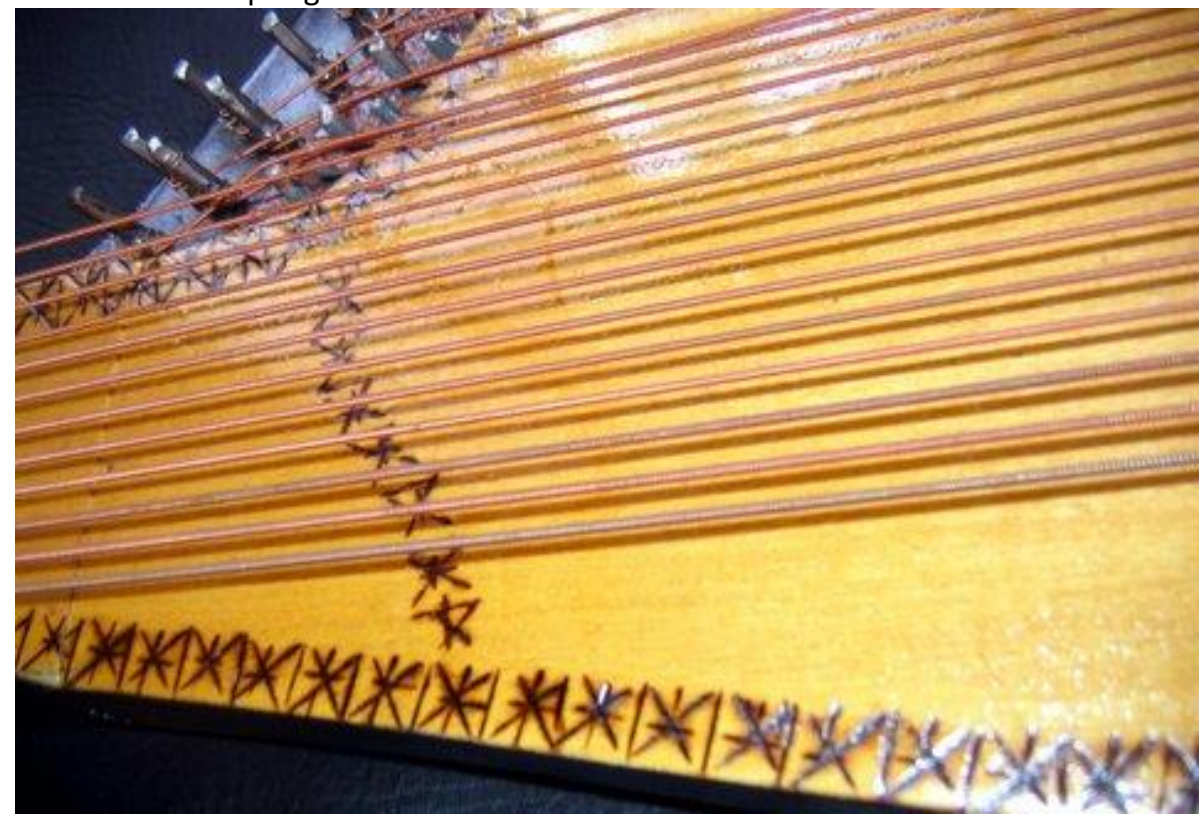

Foto: autor.

Figura 7 - Gestos

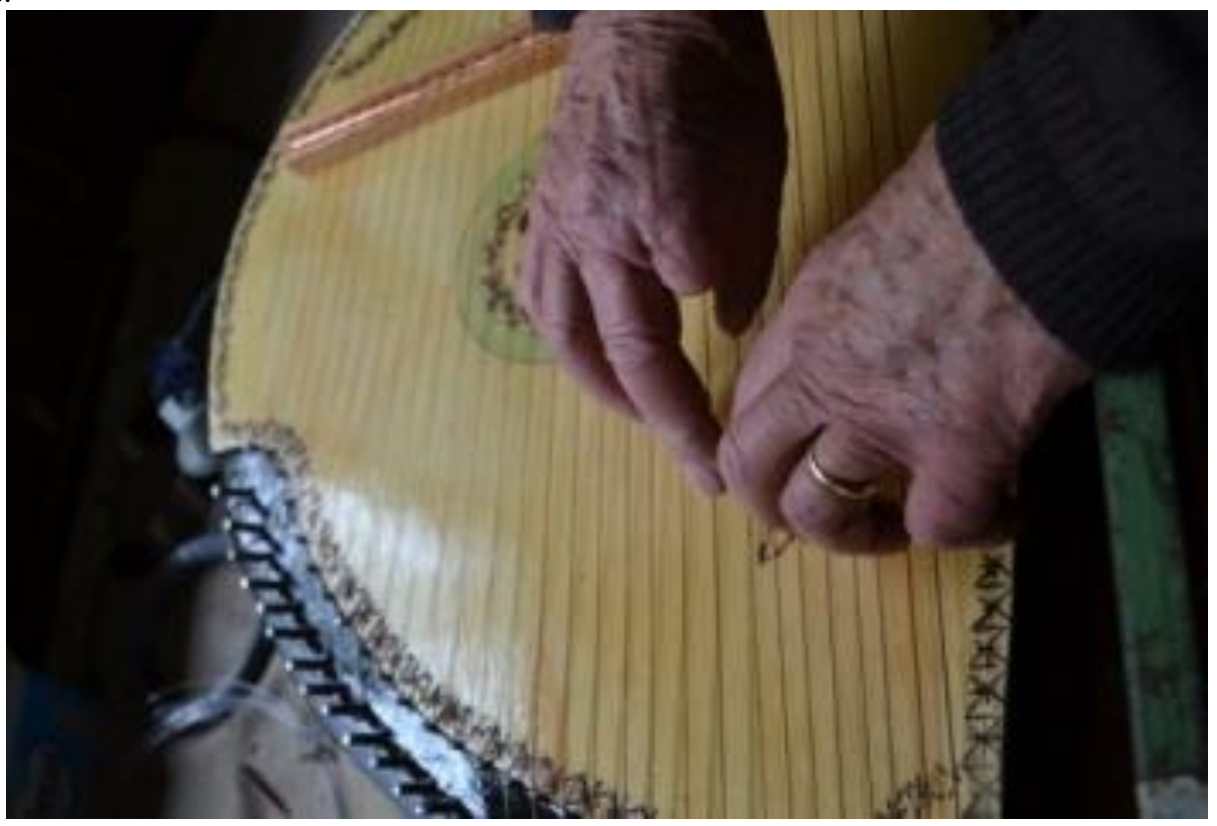

Foto: autor. 
Figura 8 - Outros instrumentos.

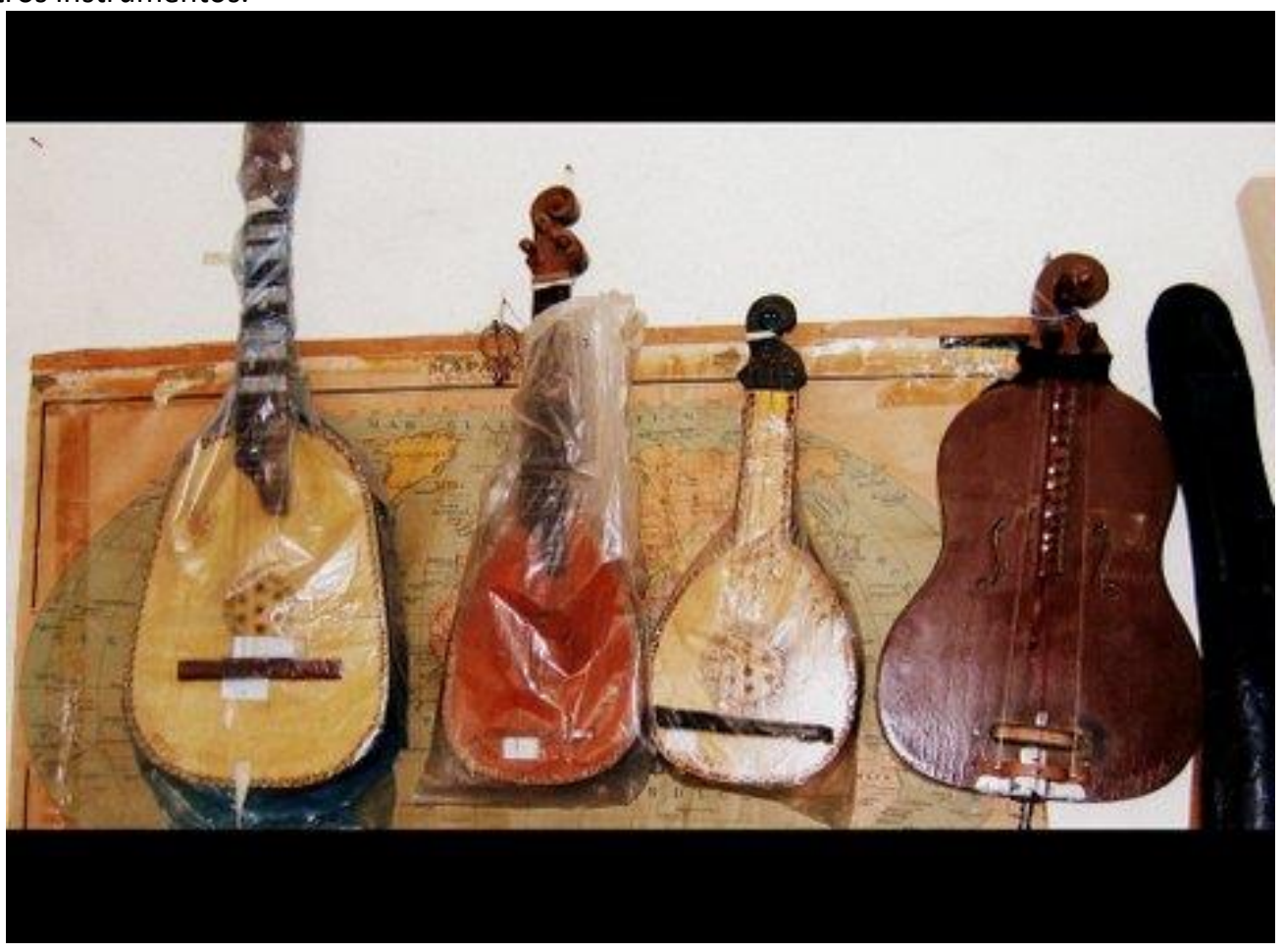

Foto: autor.

Figura 9 - Detalhe da roseta pintada.

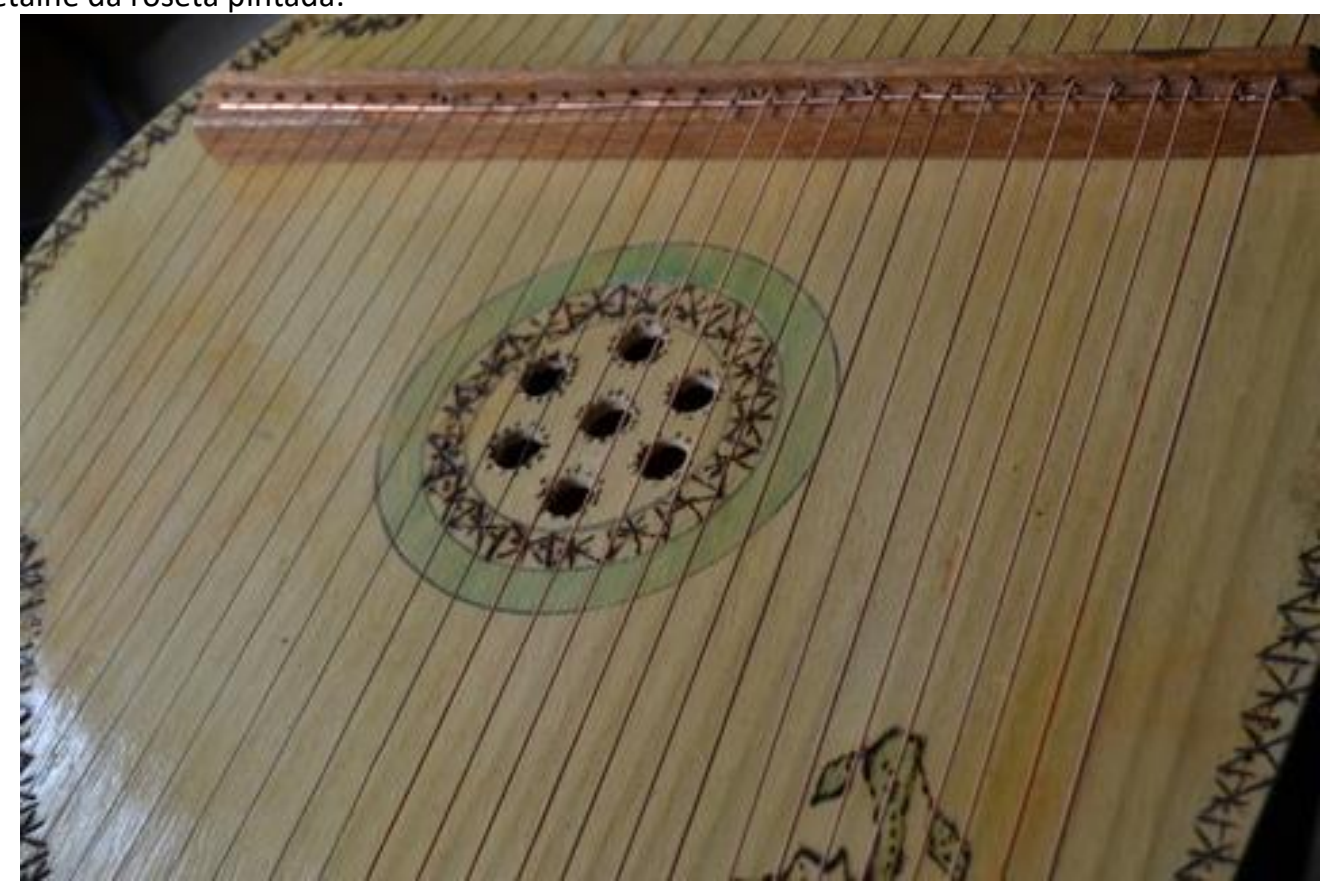

Foto: autor. 
Ivan Boiko e a Bandura: o design e a construção de instrumentos musicais como símbolo cultural Juarez Bergmann Filho

Figura 10 - Ivan e o autor.

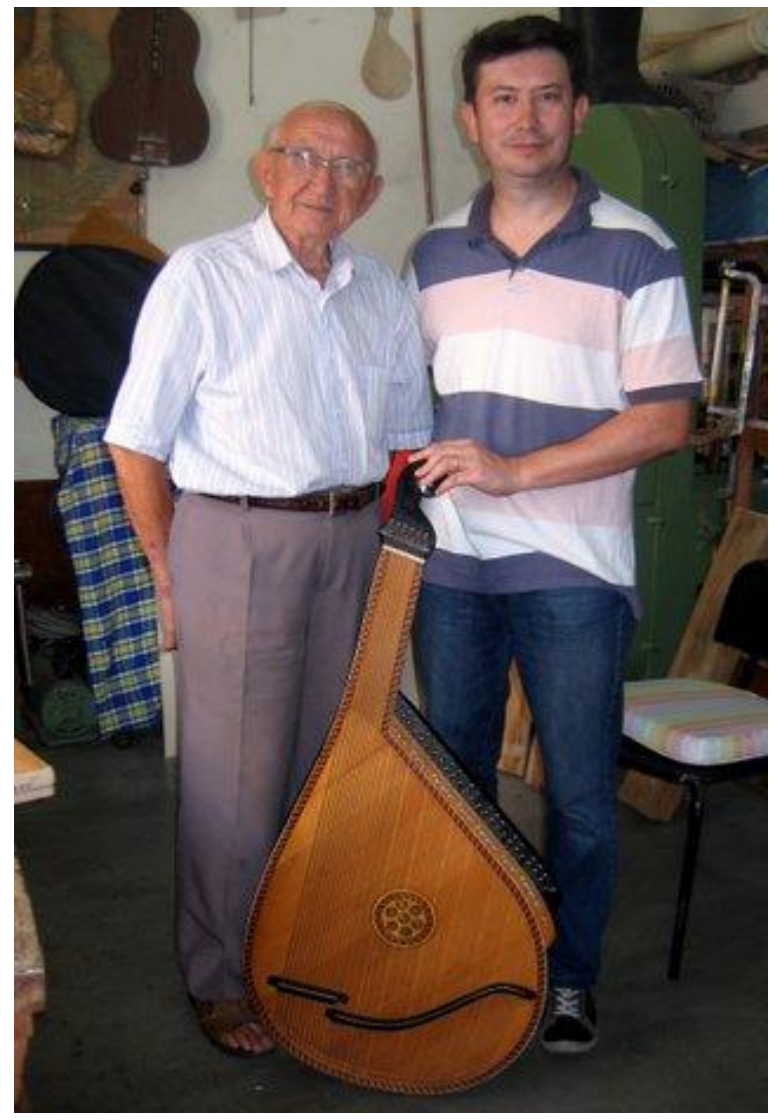

Foto: autor.

DAPesquisa, Florianópolis, v. 13, n. 21, p. 76-92, dez., 2018. ISSN 1808-3129.

DOI: http://dx.doi.org/10.5965/1808312913212018076 